\title{
A CONSTRUÇÃO DOS FATOS CIENTÍFICOS E A EXISTÊNCIA DOS VETORES DE DOENÇAS
}

\section{Márcia Grisotti}

\section{Introdução}

A importância da racionalidade técnica e científica no desenvolvimento das atividades humanas e no jogo das decisões políticas tem aumentado consideravelmente, tanto que se tornou um dos principais elementos das instituições do mundo moderno. A este respeito, Giddens menciona que um dos mecanismos do deslocamen-to (ou desencaixe) envolvido no desenvolvimento das instituições sociais modernas é o sistema de perito, ou expert systems: "sistemas de excelência técnica ou profissional que organizam grandes áreas dos ambientes material e social em que vivemos hoje" (1991, p. 35).

Contudo, pouco tem sido feito no âmbito da sociologia do conhecimento, no sentido de tornar

Artigo recebido em janeiro/2007

Aprovado em dezembro/2007 a produção científica um objeto de investigação. Este é o argumento utilizado por Latour e Woolgar em Vida de laboratório e em outras obras, para compreender os vínculos entre a prática dos pesquisadores, seus relatos e os objetos que eles produzem. Nesta obra, os autores analisaram o processo de construção de um fato/objeto - o hormônio TRF - em um laboratório de pesquisa norte-americano, com o intuito de entender como a objetividade científica é produzida, sem a pretensão de reconstruir o mundo interior, vivido pelos pesquisadores.

Algumas tentativas de explicitar a construção dos fatos científicos já foram realizadas, como, por exemplo, os livros de memórias escritos pelos próprios cientistas, a noção de estilos de pensamento e as reflexões epistemológicas sobre o diagnóstico da sífilis, desenvolvidas por Fleck (1979), além de obras cujos temas versam sobre a concorrência entre os pesquisadores, como em Bourdieu (1983, 
2004), ou sobre os laços entre as práticas dos pesquisadores e os objetos, a partir de uma abordagem da história da ciência e, nos últimos anos, da história social da ciência.

Outra tentativa de compreender esse processo encontra-se em $A$ construção social da realidade, de Berger e Luckmann, que destacam dois objetivos importantes de análise: 1) compreender a realidade de forma ao mesmo tempo objetiva e subjetiva e 2) analisar as inter-relações entre o social e o biológico.

Apesar destes autores terem explorado exaustivamente o processo da objetivação das normas sociais nos indivíduos e dos aspectos subjetivos na manutenção da ordem social, eles não forneceram pistas para se compreender como certas "verdades" são aceitas, por que um tipo de conhecimento é refutado, enquanto outro é aceito provisoriamente e, mais especificamente, como o processo de produção científica poderia tornar-se um objeto de investigação, na medida em que constrói as interpretações sobre a realidade e, conseqüentemente, estabelece normas, estatutos, entre outros.

Bloor (1991) questiona se a sociologia do conhecimento pode investigar os diversos conteúdos e a natureza do conhecimento científico. Ao sugerir a abordagem do Programa Forte (Strong Pro-

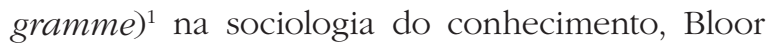
considera que todo conhecimento, seja em ciências empíricas seja em matemáticas, deve ser tratado como material para investigação. Para o autor, a filosofia tem-se ocupado da tarefa de definir o conteúdo do conhecimento, e os sociólogos têmse limitado à análise da estrutura institucional e dos fatores externos da produção científica, deixando intocada a natureza do conhecimento produzido. Vale ressaltar que Bloor resgata o estudo clássico de Durkheim - As formas elementares da vida religiosa - para mostrar como os sociólogos podem entrar nas profundezas de uma outra forma de conhecimento, de uma outra cultura.

Com base no exposto, este artigo tem por objetivo analisar as diferenças entre a construção e, portanto, a historicidade do discurso científico e os objetos da ciência, tendo como parâmetro a reflexão epistemológica de dois estudos de caso sobre a construção dos fatos científicos na área da saúde: a obra já mencionada de Latour e Woolgar (1997), entre outras, que defende a tese de uma natureza socialmente construída dos fatos científicos, e a obra de Delaporte (1999), que analisa as condições que tornaram possível a constituição da doença de Chagas no Brasil. Posteriormente, são apontados os limites da abordagem construtivista, a partir de contradições contidas, especialmente, em algumas obras de Latour.

Cabe lembrar que do amplo escopo que envolve o debate entre realismo e construtivismo pretende-se enfatizar a análise de alguns autores, porém acredita-se que tais escolhas permitem um bom rendimento analítico por ressaltarem os argumentos favoráveis à idéia de construção social dos fatos científicos, as contradições implícitas nestes argumentos e as novas questões decorrentes. Além disso, não serão discutidas todas as dimensões e as conseqüências dos autores escolhidos, mas apenas o que está vinculado ao tema central deste trabalho.

Considera-se que os estudos de Latour, juntamente com seus contemporâneos Woolgar e Callon, em vez de proporcionar uma nova visão sobre a relação entre sociedade, ciência e nature$\mathrm{za}$, retomaram antigas controvérsias encontradas em algumas contribuições da filosofia e da história da ciência, especialmente com os trabalhos de Foucault e Canguilhem e, recentemente, Delaporte. No centro dos debates está a questão: de que maneira lidar com objetos/fenômenos desconhecidos, ou não classificados ou construídos cientificamente, como certos tipos de organismos ou de seres "não-humanos" (na expressão usada por Latour), que nos colocam em situações reais, como, por exemplo, de doenças e, às vezes, de morte?

A relação entre a construção, pelos cientistas, da etiologia de uma doença e a existência natural dos vetores causadores de doenças ainda hoje é motivo de polêmica. Evitando compartilhar da tese materialista, que identifica de forma dicotômica a relação sociedade/natureza e, ao mesmo tempo, evitando compartilhar da tese de Latour, segundo a qual não existe uma realidade independente do observador, propõe-se uma abordagem intermediária que incorpore as contribuições de Canguilhem sobre a diferença, por ele traçada, entre a historicidade do discurso científico (história da ciência) e o objeto da ciência, bem como as contribuições de alguns autores situados no campo da biologia. 
Com essas contribuições, percebem-se os limites da história humana diante da história da vida. Isso, porém, não significa um reforço à antiga oposição entre sociedade (ciência) e natureza, mas, ao contrário, significa uma afirmação da interdependência entre os dois elementos, atenta, contudo, aos diferentes níveis de complexidade que os envolvem. Ou seja, ainda que mantenham as especificidades, as duas categorias estão integradas no mesmo sistema, que torna possível a vida. Para Gould (2001) e Margulis e Sagan (1997), a espécie humana é reflexo das estratégias da vida para a perpetuação, que começou no microcosmo há cerca de 3,5 bilhões de anos.

Tentar-se-á demonstrar que, embora concordando com o argumento de Latour e colegas, segundo o qual os fatos científicos são socialmente construídos, isto não significa a negação da existência de um mundo exterior, não-humano ${ }^{2}$ e objetivo, independente do conhecimento.

\section{A Vida de Laboratório e a construção dos fatos científicos}

Latour e Woolgar (1997) procuraram mostrar por meio de quais processos se chega a eliminar o contexto social e histórico de que depende a construção de um fato. Para eles, é pouco provável que os cientistas adotem o ponto de vista de que os fatos sejam socialmente construídos, já que perdura a concepção de que eles existem, sendo que o ofício dos cientistas consiste em revelar a existência deles. Para reforçar sua hipótese, os autores analisaram o contexto de pesquisa em um laboratório nos Estados Unidos, identificando quando e onde se produziu a metamorfose de um enunciado em um fato, um hormônio chamado TRF. Além de revelarem que os fatos são socialmente construídos, demonstraram que o processo de construção põe em jogo a utilização de certos dispositivos, pelos quais fica muito difícil detectar qualquer traço de sua produção, já que a estabilização de um enunciado faz com que, além de perder qualquer referência ao processo de sua construção, ele passe a ser aceito como universal. É desse modo que se caracterizaria a construção de um fato:

É como se o enunciado de origem tivesse projetado uma imagem virtual dele mesmo, que existi- ria fora dele. Antes da estabilização, os cientistas ocupavam-se de enunciados. No momento em que ela se opera, aparecem ao mesmo tempo objetos e enunciados sobre estes objetos. Um pouco depois, atribui-se cada vez mais realidade ao objeto e há cada vez menos enunciados sobre o objeto. Produz-se, conseqüentemente, uma inversão: o objeto torna-se a razão pela qual o enunciado foi formulado na origem [...]. Ao mesmo tempo, o passo se inverte. O TRF sempre existiu, simplesmente esperava para ser descoberto (Latour e Woolgar, 1997, p. 193, tradução da autora).

Os autores apontaram a dependência entre os experimentos no laboratório e o avanço do conhecimento em outros domínios da ciência, bem como demonstraram que a forma pela qual os equipamentos são utilizados no laboratório, e uma vez que se dispõe do produto final - os inscritores, no caso estudado por eles -, rapidamente é esquecido o conjunto das etapas intermediárias que tornam possível a sua produção. Segundo eles, sem os aparelhos, os fenômenos não poderiam existir:

Sem o bioteste, por exemplo, não há como dizer que uma substância existe. O bioteste não é um simples meio de obter uma substância dada de maneira independente. Ele constitui o processo de construção da substância. [...]. Construiu-se, com a ajuda dos inscritores, uma realidade artificial, da qual os atores falam como se fosse uma entidade objetiva. Essa realidade, que Bachelard (1953) chama de "fenomenotécnica", toma a aparência do fenômeno no próprio processo de sua construção pelas técnicas materiais (Idem, p. 61).

Latour e Woolgar ressaltam a tarefa do sociólogo em mostrar que a construção da realidade não deve ser, ela própria, reificada e que, para isso, é importante que sejam consideradas todas as etapas do processo de construção: "a coisa e o enunciado são correspondentes pela simples razão de que têm a mesma origem. Sua separação é apenas a etapa final do processo de sua construção" (Idem, p. 202).

É importante destacar que a relação entre objetos e enunciados já havia sido tema de estudos de alguns clássicos da sociologia. Marx (1979), no debate sobre reificação da mercadoria e Weber (1974) - porém sob uma diferente perspectiva nas reflexões sobre a distância entre a realidade 
e o conceito produzido sobre a mesma. E mais tarde, Foucault (2000) destacou que a história da formação dos conceitos não é "pedra sobre pedra", a construção de um edifício, apontando as rupturas epistemológicas e os perigos do anacronismo inerentes à análise desta história. Como exemplo, Foucault explica porque a história natural dos séculos XVII e XVIII não se serve dos mesmos conceitos do século XVI:

[...] alguns que são antigos (gênero, espécie, sinais) mudam de utilização; outros (como o de estrutura) aparecem; outros ainda (o de organismo) se formarão mais tarde. Mas o que foi modificado no século XVII e vai reger o aparecimento e a recorrência dos conceitos, para toda a história natural, é a disposição geral dos enunciados e sua seriação em conjuntos determinados; é a maneira de transcrever o que se observa [...], articular em traços distintivos [...], caracterizar e classificar; é a posição recíproca das observações particulares e dos princípios gerais; é o sistema de dependência entre o que se aprendeu, o que se viu, o que se deduz, o que se admite como provável, o que se postula (Foucault, 2000, p. 64).

Para Latour e Woolgar, o argumento de "realidade" só pode ser usado para explicar o processo pelo qual o enunciado se torna fato, ou seja, somente depois de se tornar um fato que surge o efeito de realidade, e isso se produz caso este efeito se apresente em termos de "objetividade", de "exterioridade". Para os autores, averiguar se existe ou não a realidade não é a questão: "Longe de nós a idéia de que os fatos - ou a realidade - não existem. Neste ponto, não somos relativistas. Apenas afirmamos que essa 'exterioridade' é a conseqüência do trabalho científico, e não sua causa" (Latour e Woolgar, 1997, p. 199).

Em A esperança de Pandora, Latour reforça este argumento: "Quando dizemos que não existe um mundo exterior, não negamos sua existência; ao contrário, recusamo-nos a conceder-lhe a existência a-histórica, isolada, não-humana, fria e objetiva que lhe foi atribuída" (2001a, p. 28).

Porém, o aspecto mais polêmico das obras de Latour encontra-se na análise da relação entre ciência e natureza (ou o mundo não-humano, para falar no termo por ele utilizado). Para ele, a dicotomia entre ciência e natureza é falsa:
[...] a natureza não fala dela mesma: os fatos científicos são construídos. Entre a "realidade" e o discurso sobre ela situa-se um conjunto de operações que traduzem uma equivalência e que permitem aos cientistas falar em nome da natureza, mostrando os resultados que eles obtêm em seus laboratórios (Latour e Callon, 1991, p. 8, tradução da autora).

Ou seja, o universo não-humano é socializado pelo laboratório, no qual cientistas e engenheiros trocam propriedades. Segundo o autor, por exemplo, Pasteur fez seus micróbios enquanto os micróbios "faziam seu Pasteur" (Latour, 2001b).

\section{O caso da doença de Chagas no Brasil}

Herdeiro da tradição histórico-arqueológica de Michel Foucault, bem como das análises histórico-epidemiológicas de Georges Canguilhem, atualmente professor de Filosofia na Universidade de Picardie-Jules-Verne (França), o pesquisador François Delaporte é autor de importantes estudos, com destaque para as histórias da fisiologia vegetal no século XVIII, da epidemia de cólera em Paris (1832) e da febre amarela. No estudo sobre a doença de Chagas, o autor apresenta novas interpretações sobre sua constituição no Brasil, discutindo as possibilidades e os entraves para o "descobrimento" de algo novo na ciência.

Seguindo um padrão de investigação histórico-arqueológica, que problematiza a noção de continuidade ao evidenciar a multiplicação de rupturas nas idéias (as séries, os recortes, os limites, as especificidades cronológicas, os erros, entre outros), Delaporte (1999) analisa a história de uma pesquisa, cujo projeto surgiu através do desvio de sua primeira linha de atuação, balizada por acidentes de percurso e marcada pelos jogos do acaso e do erro.

Ao contrário dos historiadores que procuram analisar os períodos históricos de forma linear, como se os episódios revelassem equilíbrios estáveis e difíceis de serem rompidos, Delaporte mostra que a necessidade, que comanda a proposição de um problema científico, os conceitos utilizados e a escolha dos meios colocados em marcha não decorrem de uma trama causal preestabelecida. Ele questiona um mito epistemológico, revelando 
que o método científico, muitas vezes, se encaixa dentro de um sistema de relações que não tem, necessariamente, um vínculo com a realização de um projeto.

No curso do estudo sobre a doença de Chagas, Delaporte analisou em profundidade o sistema lógico da descrição do ciclo do parasito, da clínica da doença e de sua epidemiologia, a partir de documentos históricos originais. Para o autor, esta pesquisa, que encontra seu objeto (um tripanossomo patogênico) e forma seu projeto (a pesquisa que ele determina), é feita a partir do acaso e do erro: em 1910, a identificação das formas flageladas no intestino do barbeiro leva à descoberta de um tripanossomo patogênico e da suposta doença que ele provocaria, a tireoidite parasitária. Mas precisou-se esperar até 1935 para se conhecer a entidade correspondente, em definitivo, à tripanossomíase americana ${ }^{3}$ atual.

Para os historiadores, segundo Delaporte, Chagas teria elucidado o ciclo evolutivo do parasito, descrito as diferentes formas clínicas da doença e anunciado a existência de um vasto flagelo. Porém, para Delaporte, essa reconstituição histórica é falsa porque oculta os erros e os acidentes ocorridos no processo de constituição ${ }^{4}$ da doença que recebeu o seu nome.

A formação do conceito de tireoidite parasitária supõe a articulação de três processos: a identificação do parasito, um estudo anatomoclínico e uma investigação epidemiológica.

Em relação à identificação do parasito, Delaporte considera que o primeiro caminho seguido por Chagas é alheio ao campo médico. A descoberta das formas critidiais no intestino do barbeiro é inicialmente associada àquela de um tripanossomo não patogênico, encontrado em um sagüi da região de Minas Gerais - Tripanosoma minasense (Chagas, 1909). Para testar sua hipótese, Chagas enviou barbeiros infectados a seu mestre Oswaldo Cruz, no Instituto de Manguinhos (RJ), para testá-los em macacos não contaminados. Assim, querendo verificar a hipótese, segundo a qual os flagelados achados no barbeiro poderiam ser formas evolutivas de Trypanosoma minasense, Chagas teria criado as possibilidades para a descoberta de um novo parasito patogênico - Trypanosoma cruzi. Surgiu, assim, de uma observação ocasional, o ponto de partida que conduziu à descoberta da doença que leva seu nome. Para Delaporte, a observação do tripanossomo patogênico deve ser atribuída a Cruz, mas as condições que tornaram possível essa observação devem ser creditadas a Chagas, que descreveu formalmente o parasito: "Na experiência é preciso distinguir dois elementos: o processo e as significações que se ligam a seu resultado" (Delaporte, 1999, p. 45, tradução da autora)

Delaporte descreve o dilema de Chagas para admitir o erro e o acontecimento imprevisto: se Chagas insistisse sobre a razão que estabelecia sua responsabilidade, ele endossaria o erro. Ou seja, admitiria a hipótese, errônea, segundo a qual as critídias seriam formas evolutivas de Trypanosoma minasense: "É o temor de se ver privado do mérito da descoberta que conduz Chagas a tentar o impossível. Substituir a sua primeira orientação de pesquisa, fictícia, segundo a qual ele tinha achado o parasita patogênico que procurava" (Idem, p. 47).

Ao dizer que os espécimes em questão haviam sido examinados antes da descrição de Trypanosoma cruzi, Chagas inverte a ordem das descobertas. A observação do Trypanosoma cruzi surge, segundo Delaporte, como a primeira etapa e parece que tudo começa com a infecção experimental do sagüi pelos barbeiros infectados: "Dizendo que sua investigação sobre Trypanosoma minasense dos macacos em Minas Gerais se dera depois da descoberta do Trypanosoma cruzi, Chagas deixa entender que ela foi feita com a única intenção de localizar um eventual tripanossoma patogênico" (Idem, p. 49).

A análise dos documentos históricos, realizada por Delaporte, evidenciou que nos relatos anteriores a 1915, Chagas ocupara-se do estudo do parasito no vetor, antes do estudo da doença. Somente após 1915 o pesquisador incorpora a seus estudos aqueles que tratam da nova patologia. A versão de Cruz, segundo a qual Chagas teria descoberto uma nova patologia e procurado o agente causal (da doença ao parasito), difere da versão de Chagas (do parasito à doença). De acordo com Delaporte, os dois não se encaixam nos acontecimentos da mesma maneira: "Se como afirma Cruz, seu aluno vai da patologia insólita em direção aos insetos infectados, a lógica impõe procurar o tripanossoma no sangue de indivíduos suspeitos" 
(Idem, p. 60). E sugere que Chagas deveria ter examinado o sangue dos indivíduos suspeitos imediatamente após a descoberta das formas critidiais no inseto. Pois, se assim fosse, ele provavelmente não teria formulado sua hipótese de as critídias serem formas evolutivas de Trypanosoma minasense.

As versões históricas, para Delaporte, ocultam a idéia segundo a qual Chagas tinha, finalmente, achado uma doença que ele, de início, não procurara. Ele analisa os aspectos políticos e culturais que impulsionaram a ocultação dos fatos. Apesar da falta de uma tradição científica e de expoentes médicos no Brasil, era preciso mostrar que o Instituto de Manguinhos, no Rio de Janeiro, propiciava as condições necessárias para a descoberta, por apresentar uma situação favorável para o desenvolvimento da produção de conhecimento científico no Brasil:

Cruz percebeu imediatamente as vantagens que tal descoberta podia proporcionar ao Instituto. Ela asseguraria uma tripla função: a profissionalização da medicina brasileira, o desenvolvimento de uma pesquisa voltada para a elucidação de patologias nacionais e a implementação de uma política de saúde pública. Ora, anunciar que a tripanossomíase americana tinha sido intuída sobre a base de um achado ocasional privaria a jovem medicina brasileira, o Instituto Oswaldo Cruz e a nova ordem higienista de um trunfo de primeira classe (Idem, p. 64).

No momento em que o jovem médico se colocava como o sucessor de Cruz, era necessário descartar a versão tão comprometedora da colaboração. Daí essas histórias transfiguradas que ocultariam o erro do qual ele precisava se libertar e o acaso do qual ele precisava tirar partido. O mestre e o discípulo esforçam-se para fazer prevalecer os direitos da lógica sobre a lógica da história (Idem, p.55).

Em relação ao estudo anatomoclínico, Delaporte considera que Chagas produziu uma quimera ao associar o bócio a um parasito, o que resultou na descrição da tireoidite parasitária.

Uma das explicações desse erro está vinculada ao fato de Chagas ter tomado como modelo explicativo o ciclo do hematozoário da malária e, conseqüentemente, está ligado à estrutura da percepção médica do período. Delaporte afirma, portanto, que a tireoidite parasitária, tal como Chagas a descreveu, não é nem tripanossomíase americana nem uma afecção endócrina e, ainda menos, as duas juntas. E lembra a ressalva de Villela, um dos críticos de Chagas, para quem os trabalhos desse pesquisador contribuíram para negligenciar o tratamento do bócio no Brasil e criaram obstáculos para a elucidação da natureza da tripanossomíase americana.

Diante desse impasse, Delaporte evidencia o tempo de latência que separa a constituição do sistema médico de Chagas da revisão epistemológica, que tornou possível a formação do conceito de tripanossomíase americana. Nesta direção, novas leituras começaram com a revisão da teoria do ciclo evolutivo do parasito, feita por Brumpt (1922 apud Delaporte, 1999), com a revisão do quadro clínico da tireoidite parasitária, feita por Krauss (1925 apud Delaporte, 1999) e com as novas enquetes epidemiológicas refeitas por pesquisadores na Argentina.

Constituiu-se um pensamento médico que se opunha à percepção de Chagas, já que este tinha formulado um estudo anatomoclínico do bócio e do cretinismo para as formas crônicas da tireoidite parasitária. Ou seja, Chagas tinha descrito duas entidades mórbidas superpostas, uma parasitose e as manifestações clássicas do hipotiroidismo.

Somente em 1930 aparecem novas contribuições fundamentais: Dias revisa o ciclo evolutivo de Trypanosoma cruzi, Pena de Azevedo revisa o material histopatológico e Lobo Leite realiza novas enquetes epidemiológicas.

Em 1935, época em que a identificação do parasito era o único indicador da doença de Chagas, Romaña, na Argentina, descreveu a síndrome óculo-palpebral e encontrou o sinal patogênico que leva seu nome. Para Delaporte, este ano não é, portanto, a data de uma redescoberta, mas o momento onde se diagnostica e se descobre a tripanossomíase americana. Com Romaña, a medicina havia mudado de terreno. Houve um deslocamento: do laboratório em Lassance, Minas Gerais, para a clínica do hospital de Santa Fé, na Argentina, onde havia casos espontâneos da doença. Há, então, uma substituição da medicina experimental pela clínica: o contato com a conjuntivite e a descoberta de que o parasita provoca a síndrome óculo-palpebral. 
Os historiadores não vêem que o corte do saber, conhecido desde 1935, não pode valer para um período anterior. É somente a partir do momento em que se identificou clinicamente a tripanossomíase americana, graças ao sinal de Romana, que é possível localizar, no discurso médico de Chagas, uma descoberta, um erro e uma confusão (Delaporte, 1999, p.69, tradução da autora).

Por fim, é preciso acrescentar que Delaporte não pretende negar o trabalho de Carlos Chagas (o qual, embora tenha construído uma doença falsa, foi o criador das condições que possibilitaram a sua descoberta e, especialmente, a descoberta do parasito), mas questionar um mito epistemológico, mostrando como a ciência pode avançar a partir do registro de erros e acasos. Além disso, coloca em evidência as razões extracientíficas para a ocultação dos erros, dos acasos e das transfigurações históricas no processo de constituição da doença de Chagas no Brasil.

\section{Limites da abordagem construtivista}

Apesar da diferença entre o estudo de Delaporte sobre a pesquisa da doença de Chagas no Brasil e o estudo de Latour e Woolgar em Vida de laboratório, no qual as políticas científicas e os investimentos financeiros para as pesquisas são bastante altos, e apesar dos períodos históricos, e, portanto, das realidades socioculturais, científicas e tecnológicas de ambos os estudos serem diferentes, encontram-se similaridades entre eles, como, por exemplo:

1. O investimento em capital simbólico. Enquanto para viabilizar o objeto de estudo de Latour (o grupo de investigadores do hormônio TRF) era importante manter o circuito de credibilidade-reconhecimento, para obter mais financiamentos para a pesquisa, o Instituto de pesquisa de Manguinhos, no Rio de Janeiro, no início da década de 1890, necessitava tornar-se reconhecido, no Brasil e no exterior, e esse foi um dos motivos, segundo Delaporte, da ocultação de muitos erros no processo de constituição da doença de Chagas.
2. O interesse de ambos os autores era a reconstrução de acontecimentos históricos, mas de um modo diferente daquele que seria do interesse dos historiadores. Eles não tentam produzir uma cronologia precisa dos acontecimentos na área, ou saber "o que realmente se passou". Interessa-lhes mostrar como um fato bruto pode ser social e historicamente desconstruído a partir da análise de microprocessos.

3. Fica muito clara, nos dois estudos, a influência dos contextos socioculturais no processo de "construção", conforme o termo utilizado por Latour, de um hormônio e de "constituição", conforme o termo utilizado por Delaporte, de uma doença.

4. Apesar de Latour, mais explicitamente, e Delaporte, implicitamente, negarem a existência de uma natureza a-histórica e independente do observador, ambos emitem afirmações que contradizem este ponto de vista.

Nas considerações finais de sua obra, Delaporte afirma: "Se não se via [a doença] não era em razão de uma observação defeituosa, mas porque ela estava invisível" (Idem, p. 182, grifo nosso).

Em uma entrevista, sob o título "Le microbe: un acteur social?", Latour enfatiza que o que Pasteur fez no laboratório foi criar novos atores, capazes de suscitar grande número de condutas humanas: férias ao livre, dormir com a janela aberta, escovar os dentes, não emprestar seu cachimbo, isolar os doentes. Porém, ao final dessa afirmação, o autor deixa transparecer o caráter limitado da produção do conhecimento, diante da complexidade da vida: "Esses atores são os micróbios que, antes de Pasteur, não tinham muita existência para os homens" (Latour, 2000, p. 302, grifo nosso, tradução da autora).

Com esta afirmação, Latour tende a contradizer o que tem constantemente enfatizado e, ao mesmo tempo, reforça o que pretenderemos defender neste artigo: antes de Pasteur a doença efetivamente não existia, porque nunca fora pensada. Ou, como ele próprio sugere: não existia para os homens! Pode-se acrescentar "nem para a ciência", o que não impede de dizer que eles existiam na natureza. E aqui voltamos ao antigo debate sobre a relação ciência e natureza. 
Para melhor entendermos essa contradição é necessário resgatar a contribuição de Canguilhem (1994) sobre a diferença entre o objeto da história da ciência e o objeto da ciência, bem como a contribuição de Gould (2001) sobre a infinita diversidade e complexidade dos organismos vivos.

Para Canguilhem, o objeto da história da ciência não tem nada em comum com o objeto da ciência:

O objeto científico, constituído pelo discurso metódico, é secundário em relação ao objeto natural, inicial, e que poderia ser chamado, em um jogo de palavras, pré-texto. A história das ciências aplicase sobre esses objetos secundários, não naturais, culturais, mas não deriva deles mais do que eles derivam dos objetos naturais. O objeto do discurso histórico é, de fato, a historicidade do discurso científico. E esta historicidade representa a efetuação de um projeto interiormente normatizado, atravessado por acidentes, retardado ou desviado por obstáculos, interrompido por crises, isto é, por momentos de julgamento e verdade (1994, p. 17, tradução da autora).

Para justificar esta afirmação, Canguilhem utiliza o exemplo da cristalografia e do cristal. Segundo ele, como o cristal é de certa forma independente do discurso científico (o qual procura obter conhecimento sobre ele), poder-se-ia chamá-lo de objeto "natural"s:

A ciência dos cristais é um discurso sobre a natureza dos cristais, a natureza não sendo nada além que sua identidade: um mineral diferente dos vegetais e dos animais, e independente de todo o uso de que o homem faz, sem que eles sejam naturalmente destinados. Quando a cristalografia, a ótica cristalina, a química mineral são constituídas como ciências, a natureza dos cristais é o conteúdo da ciência dos cristais, isto é, uma exposição de proposições objetivas obtidas por um trabalho de hipóteses e de verificações esquecidas em proveito de seus resultados. [...] Assim, o objeto cristal tem, em relação à ciência que o toma como objeto, uma independência em relação aos discursos, o que permite chamá-lo de objeto natural. Este objeto natural não é, ele mesmo, recortado e repartido em objetos e fenômenos científicos. É a ciência que constitui seu objeto a partir do momento em que inventa um método para formar, por meio de proposições capazes de serem compostas integralmente, uma teoria controlada pela preocupação em torná-la refutável (Canguilhem, 1994, p. 16, tradução da autora.)

Com base nessa diferença exposta por Canguilhem, pode-se compreender, também, a polêmica lançada por Latour (1998) sobre a morte do faraó Ramsés II, devido à tuberculose. Para esse autor, se Ramsés morreu de tuberculose há 3.000 anos atrás, como pôde morrer por causa de um bacilo somente descoberto por Koch em 1882? A resposta a esta pergunta, fornecida pelos historiadores, sugere que os objetos (bacilos) estavam lá (na época em que Ramsés estava vivo) e que os cientistas apenas os descobriram tardiamente. Para Latour, tal resposta sugere que há uma existência natural das doenças, independentemente do observador e do contexto de análise. Sugere, ainda, que se precisou esperar até 1976 para dar uma causa à morte do faraó e até 1882 para que o bacilo de Koch pudesse servir de base a essa atribuição. Latour considera que dizer que o faraó morreu de tuberculose é um anacronismo: "não se pode fazer retroagir sobre o passado uma invenção do presente. A história irreversível ignora a causalidade retrospectiva" (Latour, 1998, p. 25, tradução da autora). Para ele, portanto, há uma história da descoberta do mundo pelos cientistas, mas não há uma história do mundo por ele mesmo.

Ávila-Pires (2001) considera que quando se afirma, abreviadamente, que Ramsés II morreu tuberculoso, isso quer dizer que os restos encontrados por arqueólogos e atribuídos, com base em evidências independentes, a Ramsés II, exibiam evidências físicas que paleopatologistas puderam identificar, recentemente, como sendo compatíveis às lesões provocadas por uma infecção bacteriana, no sentido pastoriano de um bacilo que Koch descreveu em 1882. Para Ávila-Pires, a definição científica da doença e a vivência subjetiva do doente são resultantes de uma construção intelectual e socialmente condicionada. A doença é uma abstração, porém as lesões e os parasitos (e outros microorganismos) são concretos. No caso da múmia de Ramsés, e recuperando o argumento de Ávila-Pires, a doença que atualmente se descreve sob o nome de tuberculose não era conhecida no tempo dos faraós, mas as bactérias que a causam e as lesões resultantes da infecção existiam, como se pôde constatar. 
O que muda, portanto, é a história social das doenças. Esta investigará relatórios, documentos e testemunhos registrados dentro da percepção de uma certa época, lugar e visão pessoal. Estas descrições são influenciadas pela subjetividade e resultam em um constructo:

Assim, a tuberculose de hoje não é um sinônimo de phytsis do século XIX. O conceito das doenças é influenciado pela cultura e pelos hábitos e valores sociais e tradicionais. Mesmo em um mesmo lugar e época, diferentes médicos adotam critérios distintos para diagnóstico. Hipertensão, para alguns cardiologistas, é uma variação de 120 por 90 , enquanto que outros são mais estritos ou mais tolerantes (Ávila-Pires, 2001).

Segundo Ávila-Pires, se a conceituação da doença, tanto no nível individual como no nível epidemiológico, varia no tempo e no espaço, a lesão do doente é constante e objetiva, muitas vezes indelével, sobrevivendo à sua morte. Portanto, se de um lado reconhece-se o caráter construído dos fatos científicos, e especificamente neste estudo, que as doenças são construções sociais, de outro, e é aqui que se distancia de Latour (2000), reconhece-se que os parasitos e os vetores envolvidos são reais, e existem independentemente do conhecimento e da taxonomia científica ou popular. Essas diferenças aparecem quando são analisados os diferentes níveis de complexidade que envolvem a definição da doença (individual, social e ambiental).

A polêmica lançada por Latour precisa, portanto, ser posta em seu devido lugar. Ela serve para reconhecer uma tendência para a falta de percepção da distância entre o estoque de construções científicas de que se dispõe na época atual e a imensa necessidade de novas explicações sobre a diversidade e a complexidade da vida. Entende-se, nesse sentido, o conceito de vida como abrangendo todos os organismos vivos, não só a espécie humana; ou, como menciona Gould, "por mais que o amemos, o Homo sapiens não é representativo, ou simbólico, da vida como um todo" (2001, p. 31).

Gould demonstrou, amparado por outros autores, que não apenas as bactérias construíram a maior parte da história da vida, mas também que essas fundações bacterianas permanecem fortes, sadias, vigorosas e sustentando totalmente a vida multicelular. ${ }^{6}$ Segundo ele, o registro fóssil da vida começa com as bactérias, há cerca de 3,5 bilhões de anos:

As bactérias existem em número assustador e em variedade sem paralelo; vivem numa tal diversidade de ambientes e funcionam com maneiras inigualáveis de metabolismo. Nossas loucuras, nucleares ou de outros tipos, podem facilmente levar à nossa própria destruição num futuro previsível. Poderíamos levar a maior parte dos grandes vertebrados terrestres conosco - uns poucos milhares de espécies, no máximo. Certamente não conseguiríamos extirpar 500.000 espécies de escaravelhos, embora pudéssemos causar um prejuízo significativo. Duvido que pudéssemos prejudicar substancialmente a diversidade bacteriana. Os organismos modais não podem ser eclipsados pela bomba nuclear, ou mesmo afetados de modo sensível por qualquer das nossas muitas concebíveis maldades (Idem, pp. 243-244).

As bactérias, portanto, estão em todo o lugar que possa sustentar uma forma de vida. E seu número total tem sido subestimado porque nunca se pensa na amplitude de lugares que poderiam ser investigados. Gould (2001) menciona que os métodos convencionais de análise deixam escapar até 99\% desses organismos. Ou seja, a complexidade delas excede a capacidade humana de compreensão científica.

Os grandes desafios, humanos e científicos, decorrentes desta constatação, são saber lidar com as incertezas e as complexidades dos organismos vivos, na medida em que se reconhece o caráter limitado e abstrato das construções científicas diante da imensa complexidade, diversidade e variação do meio ambiente, na qual todos estão imersos e a qual se procura compreender. Além de propiciar uma percepção da complexidade da vida, que outro benefício teria a afirmação de que os fatos são cientificamente (socialmente) produzidos se, parafraseando Gould (2001), as formigas continuam a estragar nosso piquenique e as bactérias nos tomam a vida? 


\section{NOTAS}

1 Esta abordagem deve incorporar quatro valores que, de acordo com Bloor, são considerados também em outras disciplinas científicas: 1. Causalidade - interesse pelas condições que produzem as crenças e o conhecimento científico; 2. Imparcialidade - com respeito à verdade e à falsidade, à racionalidade e à irracionalidade, ao sucesso ou à falha (ambos os lados dessas dicotomias requerem explicação); 3. Simetria - os mesmos tipos de causas explicariam as crenças tanto verdadeiras quanto as falsas. Esse princípio implica a compreensão do conteúdo do conhecimento, mostrando a historicidade de sua construção e não simplesmente apresentando a ciência feita; 4. Reflexividade - os padrões e os recursos de explicação teriam que ser aplicáveis à avaliação crítica da própria sociologia da ciência.

Para Latour, o conceito não-humano somente significa alguma coisa na diferença entre o par humano-não-humano que, segundo ele, constitui uma forma de ultrapassar completamente a distinção sujeito-objeto.

3 Conhecida como doença de Chagas. Trata-se de uma paritose endêmica em amplas regiões da América, cujo agente etiológico é Tripanosoma cruzi e afeta 20 milhões de pessoas na América Latina. Para maiores detalhes ver Coura (2006).

Para evitar ambigüidades, o autor propõe falar de constituição de uma doença (que supõe um conjunto de condições de possibilidades históricas e concretas), no lugar do termo construção.

5 É interessante notar que embora Canguilhem tenha proposto a diferenciação entre a historicidade do discurso científico e os objetos da ciência, a leitura atenta de uma nota de rodapé deste mesmo livro tenderia a reacender a questão colocada atualmente pelos construtivistas: "Sem dúvida, um objeto natural não é naturalmente natural, ele é objeto da experiência habitual e da percepção de uma cultura" (Canguilhem, 1994, p. 16).

6 Gould cita vários exemplos sobre a quantidade e os lugares tolerados pelas bactérias. Durante o decurso de uma vida, o número de E. coli nos intestinos de cada ser humano excede em muito o número total de pessoas que vivem atualmente ou que já habitaram a terra (e E. coli é apenas uma das espécies na "flora" intestinal normal de to-dos os seres humanos). Com base nos trabalhos de Margulis e Sagan (1997), este autor relembra que as bactérias vivem aos "bilhões" em um grama de solo fértil e em milhões em uma gota de saliva que a pele hu- mana abriga cerca de 100.000 micróbios por centímetro quadrado e que uma colher de solo de boa qualidade contém cerca de 10 trilhões de bactérias (Gold, 2001).

\section{BIBLIOGRAFIA}

AVILA-PIRES, Fernando. D. (2001), "Saúde, doença e teoria de sistemas". Actas do I Congresso Luso-brasileiro de História Ciência e Tecnologia. Universidade de Évora, pp. 606-614.

BERGER, Peter L. \& LUCKMANN, Thomas. (1985), A construção social da realidade. Tradução de Floriano de Souza Fernandes. 19 ed. Petrópolis, Vozes.

BLOOR, David. (1991), Knowledge and social imagery. Londres, University Chicago Press.

BOURDIEU, Pierre (1983), Bourdieu (org. Renato Ortiz). 2 ed. São Paulo, Ática (col. Grandes Cientistas Sociais).

(2004), Os usos sociais da ciência: por uma sociologia clínica do campo cientifico. Tradução de Denice Barabara Catani. São Paulo, Editora da Unesp.

CANGUILHEM, Georges. (1994), Études d'bistoire et de philosophie des sciences. Paris, PUF.

(1998), La connaissance de la vie. 10 ed. Paris, Vrin.

COURA, J. Rodrigues (org.). (2006), Dinâmica das doenças infecciosas e parasitarias. Rio de Janeiro, Guanabara Koogan.

DELAPORTE, François. (1999), La maladie de Chagas. Paris, Payot.

(2001), A vital rationalist. Selected writings from Georges Canguilhem. Nova York, Urzone.

DURKHEIM, Émile. (1989), As formas elementares de vida religiosa. (Tradução de Joaquim Pereira Neto). São Paulo, Edições Paulinas.

FLECK, L. (1979), Genesis and development of a scientific fact. Chicago, University of Chicago Press. 
FOUCAULT, Michel (2000), A arqueologia do saber. Tradução de Luiz Felipe Baeta Neves. 6 ed. Rio de Janeiro, Forense Universitária.

GIDDENS, Anthony. (1991), As conseqüências da modernidade. (Tradução de Raul Fiker). 2 ed. São Paulo, Martins Fontes.

GOULD, Stephen J. (2001), Lance de dados: a idéia de evolução de Platão a Darwin. Tradução de Sérgio Moraes Rego. Rio de Janeiro, Record.

LATOUR, Bruno. (1983). Petites leçons de sociologie des sciences. Paris, La Découverte. . (1998), "Ramsés, Il est-il mort de tuberculose?”. La Recherche, 307: 34-36.

. (2000), "Le microbe: un acteur social?", in Philippe Cabin e Jean-François Dortier (orgs.), La sociologie: histoire et idées, Paris, Editions Sciences Humaines, pp. 299-304.

. (2001a), A esperança de Pandora. (tradução de Gilson César Cardoso de Sousa). São Paulo, Edusc.

. (2001b), Pauster: guerre et paix des microbes suivi de irréductions. Paris, La Découverte.

LATOUR, Bruno \& CALLON, Michel. (1991), La science telle qu'elle se fait: anthologie de la sociologie des sciences de langue anglaise. Paris, La Découverte.

LATOUR, Bruno \& WOOLGAR, Steve. (1997), Vida de laboratório. Tradução de Angela Ramalho Vianna. Rio de Janeiro, Relume Dumará.

MARGULIS, Lynn \& SAGAN, Dorion. (1997), Microcosmos: four billion years of microbial evolution. California, University of California Press.

MARX, Karl. (1979), "Fetichismo e reificação", in Octavio Ianni (org.), Karl Marx: sociologia, São Paulo, Ática.

WEBER, Max. (1974), Sobre a teoria das ciências sociais. Lisboa, Presença. 


\section{A CONSTRUÇÃO DOS FATOS CIENTÍFICOS E A EXISTÊNCIA DOS VETORES DE DOENÇAS}

\section{Márcia Grisotti}

Palavras-chave: Construção social das doenças; Vetores de doenças; Construtivismo; História da ciência; Doença de Chagas.

Este artigo analisa as diferenças entre a construção do discurso científico e os objetos da ciência, tendo como parâmetro a reflexão epistemológica de dois estudos: a obra de Latour e Woolgar (1997), que defende a tese de uma natureza socialmente construída dos fatos científicos, e a obra de Delaporte (1999), que analisa as condições que tornaram possível a constituição da doença de Chagas no Brasil. Posteriormente, apontamse os limites da abordagem construtivista a partir da questão central de como lidar com objetos e fenômenos desconhecidos (não classificados, ou construídos cientificamente), como certos tipos de organismos ou de seres "não-humanos", que nos colocam em situações reais, por exemplo, de doenças e, às vezes, de morte.
THE CONSTRUCTION OF SCIENTIFIC FACTS AND THE EXISTENCE OF DISEASE VECTORS

\section{Márcia Grisotti}

Keywords: Social construction of disease; Disease vectors; Constructionism; History of Science; Chagas disease.

The article analyses the difference between the construction of scientific discourse and objects of science. For such, two studies are used as parameters for epistemological reflection. The first is the work of Latour and Woolgar (1997) which defends the thesis of the socially constructed nature of scientific facts. The second is the work of Delaporte (1999) that analyses the conditions which made the characterization of Chagas disease possible. The article uses the fundamental question of how to deal with unknown (or not yet scientifically constructed) objects and phenomena, such as certain types of organisms or "non-human" beings, which place us in real situations, such as "life or death," to highlight the limits of the constructionist approach.

\section{LA CONSTRUCTION DES FAITS SCIENTIFIQUES ET L'EXISTENCE DES VECTEURS DE MALADIES}

\section{Márcia Grisotti}

Mots-clés: Construction sociale de la maladie; Vecteurs des maladies; Constructivisme; Histoire de la science; Maladie de Chagas.

L'article analyse les différences entre la construction du discours scientifique et les objets de la science à partir de la réflexion épistémologique de deux études: l'œuvre de Latour et Woolgar (1997), qui défend la thèse d'une nature socialement construite de faits scientifiques, et l'œuvre de Delaporte (1999), qui analyse les conditions qui ont rendu possible la constitution de la maladie de Chagas au Brésil. L'article indique, ensuite, certaines limites de l'approche constructiviste à partir de la question centrale: comment travailler avec des objets et des phénomènes inconnus (non classifiés ou qui ont été construits scientifiquement), comme certains types d'organismes ou d'êtres "non humains", qui nous mènent à des situations réelles comme, par exemple, les maladies et, parfois, la mort. 